\title{
Pharmacokinetic of Diclofenac in the Presence and Absence of Glibenclamide in the Rat
}

\author{
María R. León-Reyes ${ }^{1}$, Gilberto Castañeda-Hernández ${ }^{2}$ and Mario I. Ortiz ${ }^{3}$ \\ ${ }^{1}$ Sección de Estudios de Postgrado e Investigación. Escuela Superior de Medicina. Instituto Politécnico Nacional, México, \\ D.F., Mexico; ${ }^{2}$ Sección Externa de Farmacología, Centro de Investigación y de Estudios Avanzados del Instituto \\ Politécnico Nacional, México, D.F., Mexico; ${ }^{3}$ Área Académica de Medicina del Instituto de Ciencias de la Salud, \\ Universidad Autónoma del Estado de Hidalgo, Pachuca, Hidalgo, Mexico.
}

Received, May 3, 2009, Revised, June 17, 2009, Accepted, September 28, 2009, Published, September 29, 2009.

\begin{abstract}
Purpose. There is evidence that the sulfonylurea antidiabetic agent glibenclamide reduces the analgesic action of non-steroidal anti-inflammatory drugs (NSAIDs), opioids and neuromodulators in animal models. Therefore, in view of the vast clinical uses and interactions of NSAIDs with commonly used therapeutic agents, the interaction of the NSAID diclofenac and glibenclamide was investigated about pharmacokinetic profile and antinociceptive effect in rats. Methods. Antinociception was assessed using the formalin test. Fifty microliters of diluted formalin was injected s.c. into the dorsal surface of the right hind paw. Nociceptive behavior was quantified as the number of flinches of the injected paw during $60 \mathrm{~min}$ after injection. Rats were treated with oral administration of vehicle or increasing doses of diclofenac $(3-18 \mathrm{mg} / \mathrm{kg}$ ) before formalin injection. To determine the pharmacodynamic interaction between diclofenac and glibenclamide, the effect of oral administration of glibenclamide $(1-30 \mathrm{mg} / \mathrm{kg})$ on the antinociceptive effect induced by diclofenac (18 $\mathrm{mg} / \mathrm{kg}$, p.o.) was assessed. To evaluate the pharmacokinetic interaction between diclofenac and glibenclamide, the effect of glibenclamide $(10 \mathrm{mg} / \mathrm{kg}$, p.o.) on the pharmacokinetic of diclofenac $(18 \mathrm{mg} / \mathrm{kg}$, p.o.) was studied in the rat. Blood samples were taken over $8 \mathrm{~h}$ and analyzed using a validated high-performance liquid chromatography method to generate the pharmacokinetic profile of diclofenac. Pharmacokinetic parameters were estimated using noncompartmental analysis. Results. Systemic administration of diclofenac produced a dose-dependent antinociceptive effect in the formalin test. Systemic treatment with glibenclamide prevented diclofenac-induced antinociception. In pharmacokinetic interaction study, no significant $(\mathrm{P}>0.05)$ change in diclofenac concentration-time profiles in the presence of glibenclamide was detected. Conclusion. The experimental findings suggest that systemic glibenclamide is able to block the diclofenac-induced antinociception in the rat formalin test. Besides, this antagonism was not produced by diminution in the bioavailability of diclofenac. Likewise, the validated assay had sufficient accuracy and precision for pharmacokinetic determination of diclofenac in the rat.
\end{abstract}

\section{INTRODUCTION}

Diclofenac is a non-steroidal anti-inflammatory drug (NSAID) that exhibits potent analgesic and anti-inflammatory properties. Diclofenac administered orally, rectally or intramuscularly has showed to have clinical efficacy in patients with rheumatoid arthritis, osteoarthritis, ankylosing spondylitis and other inflammatory conditions (1). It is known that diclofenac, as other nonselective NSAIDs, is able to impair prostaglandin synthesis by the inhibition of the cyclooxygenase isozymes COX-1 and COX-2 in both, the injured tissue and the central nervous system $(2,3)$. However, there is evidence that additional prostaglandin-independent mechanisms are involved in the antinociceptive action of diclofenac at both, the peripheral and central levels. In this respect, it has been proven that the local peripheral administration of glibenclamide is able to block the peripheral antinociceptive effect of diclofenac in the rat (4-6),

\footnotetext{
Corresponding Author: Mario I. Ortiz, Ph.D., Laboratorio de Farmacología, Área Académica de Medicina del Instituto de Ciencias de la Salud, Universidad Autónoma del Estado de Hidalgo. Eliseo Ramírez Ulloa 400, Colonia Doctores. Pachuca, Hidalgo. 42090, Mexico, E-mail: mario_i_ortiz@hotmail.com
} 
suggesting the participation of ATP-sensitive $\mathrm{K}^{+}$ channels in its antinociceptive effect at peripheral level.

Diclofenac undergoes first-pass metabolism and the oral bioavailability of diclofenac ranges from 54 to $90 \%$ (7). Diclofenac is highly bound to serum proteins $(\geq 99.5 \%)$ and it has a relatively low volume of distribution $(0.12$ to $0.17 \mathrm{~L} / \mathrm{kg})(1,7)$. There are little data about the distribution of diclofenac into other tissues and fluids. About this, diclofenac easily penetrates the synovial fluid and cross the placenta $(1,8)$. However, diclofenac does not easily cross the blood-brain barrier. It has been tested that the diclofenac concentrations in cerebrospinal fluid are $8.22 \%$ of those in plasma (9). There are reports wherein the antiinflammatory and antinociceptive effect of diclofenac cannot be directly explained by circulating concentrations in animals (10) or in humans (1). Therefore, we think the diclofenac effects are mainly mediated via a local action in target tissues.

Drug interaction is a modification of the effect of a drug when administered with another drug. The interaction between drugs may be pharmacokinetic and/or pharmacodynamic. The effect may be an increase or a decrease in the action and/or bioavailability of either substance. In this respect, it has been shown that colestipol and cholestyramine decreased the area under the concentration-time curve (AUC) and the maximum concentration (Cmax) of diclofenac in humans (11). Likewise, administration of aspirin in healthy subjects reduced diclofenac plasma concentrations, peak plasma levels, and AUC values (1). However, there is not any pharmacokinetic study on the interaction between the ATP-sensitive $\mathrm{K}^{+}$channels inhibitor glibenclamide (12) and diclofenac. Therefore, the main of the present study was determine whether the systemic administration (oral) of the sulfonylurea antidiabetic agent and ATP-sensitive $\mathrm{K}^{+}$channel blocker glibenclamide is able to modify the pharmacokinetic and pharmacodynamic of diclofenac in the rat.

\section{MATERIAL AND METHODS}

\section{Animals}

Female Wistar rats (of mixed estrous phases) aged 8-10 weeks (weight range, 180-200 g) from our own breeding facilities were used in this study.
Animals had free access to drinking water, but food was restricted $12 \mathrm{~h}$ before the experiments. Efforts were made to minimize animal suffering and to reduce the number of animals used. Rats were used once only. At the end of the experiments the rats were sacrificed in a $\mathrm{CO}_{2}$ chamber. All experiments followed the Guidelines on Ethical Standards for Investigation of Experimental Pain in Animals (13). Additionally, the study was approved by the Institutional Animal Care and Use Committee (CINVESTAV-IPN, México, D.F., Mexico).

\section{Pharmacodynamic study}

\section{Drugs}

Diclofenac and glibenclamide were purchased from Sigma (St. Louis, MO, USA). Diclofenac was dissolved in saline. Glibenclamide was dissolved in $0.05 \%$ carboxymethylcellulose.

\section{Measurement of antinociceptive activity}

Pain and antinociception were assessed by the formalin test, as previously described $(4,5,14)$. Briefly, fifty microliters of diluted formalin (1\%) were injected subcutaneously (s.c.) to the dorsal surface of the right hind paw, and the resulting flinching behavior was considered as an expression of nociception. Numbers of flinches against time curves were constructed, these curves being biphasic. The initial acute phase $(0-10 \mathrm{~min})$ was followed by a short quiescent period followed by a prolonged tonic response $(15-60 \mathrm{~min})$. The area under the curve for both phases was estimated, and a significant area reduction was interpreted as antinociception.

\section{Study design}

To evaluate the effect of glibenclamide on the systemic antinociceptive action of diclofenac in the formalin test, rats received the oral administration (p.o.) of the appropriate vehicle or increasing doses of diclofenac $(3-18 \mathrm{mg} / \mathrm{kg}) 30 \mathrm{~min}$ before formalin injection. After formalin injection, flinching behavior was assessed for the next $60 \mathrm{~min}$. To determine whether diclofenac-induced systemic antinociception was mediated by $\mathrm{K}^{+}$channel activation, effect of co-treatment with the appropriate vehicle or glibenclamide $(1-30 \mathrm{mg} / \mathrm{kg}$, p.o.) on the systemic antinociceptive effect induced by diclofenac (18 mg/kg, p.o.) was assessed. Drugs were administrated in a volume of $4 \mathrm{~mL} / \mathrm{kg}$, p.o. 
Doses and drug administration schedule of diclofenac and glibenclamide were selected based on previous reports $(4-6,14,15)$ and on pilot experiments in our laboratory. Rats in all groups were observed regarding behavioral or motor function changes induced by the treatments. This change was assessed, but not quantified, by testing the animals' ability to stand and walk in a normal posture. All observations were carried out by a blinded investigator.

\section{Data analysis and statistics}

Results are given as the mean \pm SEM for 6 animals per group. Curves were constructed plotting the number of flinches as a function of time. The area under the number of flinches against time curves (AUC), an expression of the duration and intensity of the effect, was calculated by the trapezoidal rule. Reduction of number of flinches or AUC of the second phase is reported only, because diclofenac did not produce any change on phase 1 . Analysis of variance (ANOVA), followed by Tukey's test was used to compare differences between treatments. Differences were considered to reach statistical significance when $p<0.05$.

\section{Pharmacokinetic study}

\section{Surgery}

The rats were anesthetized with ethyl ether. Then, PE catheters (a combination of PE-10 and PE-50 was used; I.D. $0.28 \mathrm{~mm}$, O.D. $0.61 \mathrm{~mm}$; I.D. 0.58 $\mathrm{mm}$, O.D. $0.965 \mathrm{~mm}$, respectively; Clay Adams, Parsippany, NJ) were surgically implanted into the caudal artery for the collection of blood samples as reported previously (16).

\section{Chemicals}

Diclofenac, naproxen and glibenclamide were purchased from Sigma (St. Louis, MO, USA). Acetonitrile and methanol were chromatographic grade (Merck, Darmstadt, Germany). Deionized water was obtained using a Milli-Q system (Continental Water Systems, El Paso, TX). Other reagents used in the study were of analytical grade. Diclofenac and glibenclamide were dissolved in saline and $0.05 \%$ carboxymethylcellulose, respectively.

\section{Study design}

In this study, only circulating concentrations of diclofenac were estimated in the animals. To address this issue, the pharmacokinetic parameters of diclofenac in rats at its antinociceptive dose were generated for baseline information. Thereafter, the pharmacokinetic of diclofenac was investigated in the presence of glibenclamide. For this purpose, following a single oral dose of diclofenac (18 $\mathrm{mg} / \mathrm{kg})$ with or without glibenclamide $(10 \mathrm{mg} / \mathrm{kg}$, p.o.), blood samples $(100 \mu \mathrm{L})$ were drawn before and at $2.5,5,7.5,10,15,20,30,45,60,120,240$, 360 and $480 \mathrm{~min}$ after dosing. Blood samples were frozen at $-70^{\circ} \mathrm{C}$ until analyzed for diclofenac by HPLC.

\section{Analysis of diclofenac in blood}

Blood concentrations of diclofenac were determined by a HPLC method developed in our laboratory. Briefly, whole-blood samples $(100 \mu \mathrm{L})$ were placed into $2 \mathrm{~mL}$ Eppendorf tubes, and 0.1 $\mathrm{ng} / \mathrm{mL}$ of naproxen (internal standard) was added. Blood was then acidified by the addition of $20 \mu \mathrm{L}$ of $0.5 \mathrm{M} \mathrm{NaH}_{2} \mathrm{PO}_{4}(\mathrm{pH} \mathrm{3})$. Next $1 \mathrm{~mL}$ of ethyl acetate was added, and samples were extracted by agitation in vortex at maximal speed for $1 \mathrm{~min}$. After centrifugation at $10,000 \mathrm{rpm}$ for $10 \mathrm{~min}$, the organic layer was transferred into a clean conical glass tube and evaporated to dryness in a water bath at $50^{\circ} \mathrm{C}$ under a gentle nitrogen stream. The dry residue was redissolved in $200 \mu \mathrm{L}$ of a mixture of $0.075 \mathrm{M} \mathrm{Na}_{2} \mathrm{HPO}_{4}$ buffer (pH 7) and methanol $(1: 1)$, and $100-\mu \mathrm{L}$ aliquots were injected into the chromatographic system.

The chromatographic system consisted of a model 510 solvent delivery system (Waters Assoc., Milford, MA), a 7125 Rheodyne injector with a 100-mL loop (Cotati, CA) and a LC-4B electrochemical detector (BAS, West Lafayette, IN) with a glassy carbon working electrode and an $\mathrm{Ag} / \mathrm{AgCl}$ reference electrode. Compounds were separated at room temperature on a MicroPak C18 column of $300 \mathrm{~mm} \mathrm{X} 4 \mathrm{~mm}$ I.D. and particle size of $10 \mu \mathrm{m}$ (Varian, Palo Alto, CA) eluted with a mixture of $0.075 \mathrm{M}$ sodium acetate (adjusted to $\mathrm{pH}$ 3.3 with glacial acetic acid) and acetonitrile (55:45, $\mathrm{v} / \mathrm{v}$ ) at a flow rate of $2 \mathrm{~mL} / \mathrm{min}$. The detector was operated at $+1.1 \mathrm{~V}$, and the chromatograms were registered in a Servogor 120 (Norma Goerz Instruments, Elik Grove Village, IL). Diclofenac pharmacokinetic parameters were performed by 
non-compartmental analysis using WinNonlin software, version 3.0 (Pharsight Corp, Mountain View, CA).

\section{Statistical analysis}

Data are expressed as mean value \pm SEM. The data obtained were subjected to one-way ANOVA followed by Tukey's test and Student's " $t$ "-test to determine the level of significance and a $P$ value of $<0.05$ was considered as statistically significant.

\section{RESULTS}

\section{Pharmacodynamic interaction between diclofenac and glibenclamide}

Formalin administration produced a typical pattern of flinching behavior. Systemic (oral) administration of diclofenac significantly reduced the number of flinches during phase two $(p<0.05)$ (Figure 1), but not during phase one (data not shown). Systemic pretreatment with the ATPsensitive $\mathrm{K}^{+}$channel inhibitor glibenclamide was able to reverse $(p<0.05)$ diclofenac-induced antinociception (systemic) (Figure 1).

\section{Assay Validation}

Diclofenac pharmacokinetic was performed with a high-performance liquid chromatograph in blood. The assayed method was validated before use. The method showed specificity and good precision; the repeatability and reproducibility were within acceptable limits in quality control samples at low, medium and high concentration levels.

The retention times were 1.6 and $3.5 \mathrm{~min}$ for naproxen and diclofenac, respectively. The peaks were resolved with no interfering peaks (data no shown). Calibration curves were constructed for diclofenac concentrations in blood ranging from 0.1 to $12 \mu \mathrm{g} / \mathrm{mL}$. A linear relationship $\left(\mathrm{r}^{2}=0.9996\right)$ was obtained when peak-height ratios of diclofenac to the internal standard were plotted against diclofenac blood concentration. Coefficients of variation were always lower than $10 \%$, whereas accuracy ranged from $90 \%$ to $115 \%$. The detection limit of the method was $50 \mathrm{ng} / \mathrm{mL}$.

\section{Pharmacokinetic interaction between diclofenac and glibenclamide}

Following a single oral dose of $18 \mathrm{mg} / \mathrm{kg}$ diclofenac alone, the drug was monitored up to $8 \mathrm{~h}$. Figure 2 shows the mean $( \pm$ SEM) diclofenac plasma concentration vs. time profiles after oral dosing of diclofenac at $18 \mathrm{mg} / \mathrm{kg}$ alone, or when coadministered with glibenclamide $(10 \mathrm{mg} / \mathrm{kg}$, p.o.) in rats. The pharmacokinetic parameters of diclofenac with and without co-administered glibenclamide are summarized in table 1 . No significant $(\mathrm{P}>0.05)$ change in diclofenac concentration-time profiles in the presence of glibenclamide was detected.

\section{DISCUSSION}

\section{Pharmacodynamic interaction study}

The results reported here suggest that modulation of some $\mathrm{K}^{+}$channels at systemic level represent an important step in the mechanism of antinociception induced by diclofenac. Our data demonstrate that the systemic administration of the ATP-sensitive $\mathrm{K}^{+}$ channels inhibitor glibenclamide prevented the diclofenac-induced antinociception. In according to these results, it has been proven that local peripheral administration of glibenclamide was able to prevent the antinociceptive and antihyperalgesic effects of diclofenac (4-6). To our knowledge, this is the first report indicating that systemic glibenclamide is able to block the analgesic effect induced by systemic diclofenac in the rat formalin test. In the same line, recently we had demonstrated that systemic glibenclamide blocked the antihyperalgesic effect of diclofenac in the mouse (17). At the concentrations used in this work, the $\mathrm{K}^{+}$ channel blocker glibenclamide did not modify the flinching behavior of rats in comparison with that of control rats. The lack of effect of the $\mathrm{K}^{+}$channel blocker is consistent with the results of studies in which glibenclamide not modify the nociceptive activity of chemical, thermal noxious stimuli and mechanical hyperalgesia $(4-6,15,18)$, thus excluding the possibility that the prevention of diclofenac antinociception could be due to a hyperalgesic or nociceptive effect of glibenclamide.

\section{Pharmacokinetic interaction study}

In the present study, rats were orally administered with diclofenac and glibenclamide and the former was monitored up to $8 \mathrm{~h}$. Although the administration of glibenclamide increased the Cmax of diclofenac from $10.1 \pm 1.1 \mu \mathrm{g} / \mathrm{mL}$ to $11.9 \pm 0.9$ $\mu \mathrm{g} / \mathrm{mL}$, this was not a significant effect $(\mathrm{P}>0.05)$. On the contrary, glibenclamide was able to decrease the Tmax of diclofenac of $12.1 \pm 3.6$ min to $9.6 \pm$ $0.4 \mathrm{~min}$, however, this change was not significant 

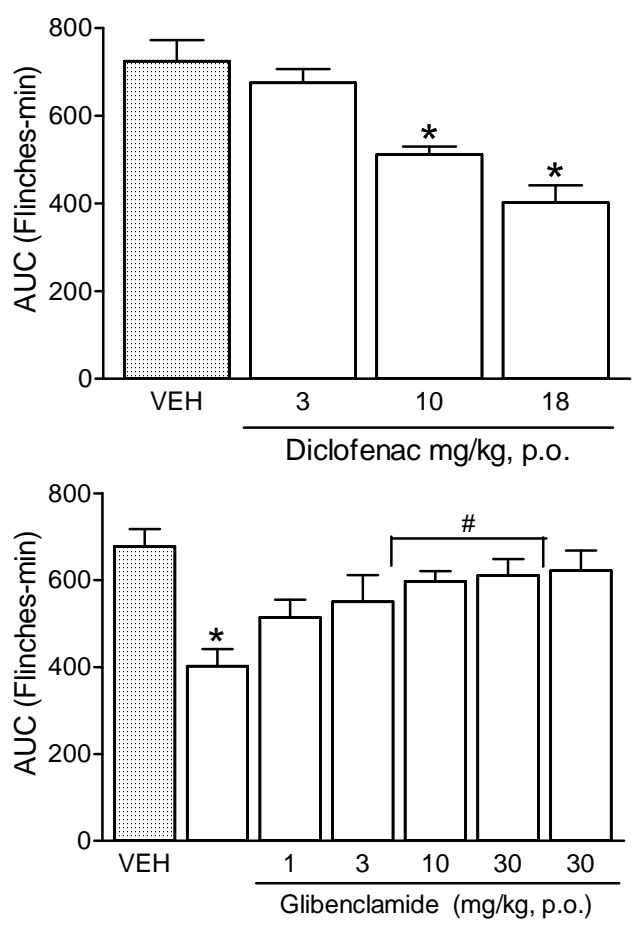

Diclofenac $18 \mathrm{mg} / \mathrm{kg}$, p.o.

Figure 1. Antinociceptive effect induced by systemic diclofenac during the second phase of the formalin test (top panel) and effect of the ATP-sensitive $\mathrm{K}^{+}$channel inhibitor glibenclamide on the systemic antinociception produced by diclofenac during the second phase of the formalin test (bottom panel). Data are expressed as the area under the number of flinches against time curve (AUC). Bars are the mean \pm SEM for 6 animals. * Significantly different from vehicle group $(P<0.05)$ and ${ }^{\#}$ significantly different from the diclofenac group $(P<0.05)$, as determined by analysis of variance followed by Tukey's test.

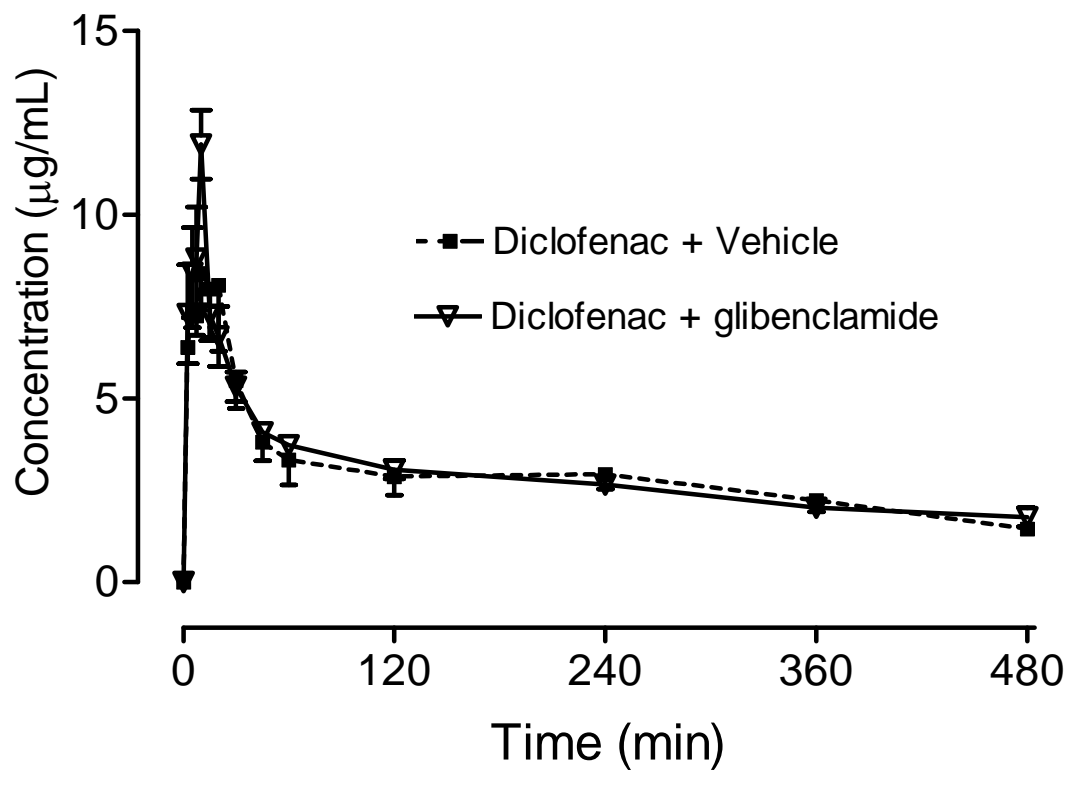

Figure 2. Mean plasma concentration-time curves in rat after single oral administration of $18 \mathrm{mg} / \mathrm{kg}$ diclofenac or with $10 \mathrm{mg} / \mathrm{kg}$ oral dose of glibenclamide. Data are the mean \pm SEM for 6 rats. 
Table 1. Pharmacokinetic parameters of diclofenac after single oral dose of $18 \mathrm{mg} / \mathrm{kg}$ alone or in the presence of glibenclamide at $10 \mathrm{mg} / \mathrm{kg}$ orally in rat.

\begin{tabular}{ccccc}
\hline Treatment & $\begin{array}{c}\mathrm{Cmax} \\
(\mu \mathrm{g} / \mathrm{mL})\end{array}$ & $\begin{array}{c}\text { Tmax } \\
(\min )\end{array}$ & $\begin{array}{c}\mathrm{AUC}_{0-\mathrm{t}} \\
(\mu \mathrm{g} \min / \mathrm{mL})\end{array}$ & $\begin{array}{c}\mathrm{AUC}_{0-\infty} \\
(\mu \mathrm{g} \mathrm{min} / \mathrm{mL})\end{array}$ \\
\hline $\begin{array}{c}\text { Diclofenac }+ \text { vehicle } \\
\text { Diclofenac }+\end{array}$ & $10.1 \pm 1.1$ & $12.1 \pm 3.6$ & $1400.8 \pm 170.0$ & $1985.5 \pm 184.2$ \\
Glibenclamide & $11.9 \pm 0.9$ & $9.6 \pm 0.4$ & $1403.0 \pm 62.5$ & $2399.1 \pm 305.8$ \\
\hline
\end{tabular}

The results for Cmax, Tmax and AUC are given as mean \pm SEM of six repetitions for each treatment.

( $>00.05)$. Likewise, there was no significant change in the AUC of diclofenac due to glibenclamide coadministration.

Most drug-drug interactions are caused by the inhibition of metabolism of one drug by a concomitantly administered drug. Clinically, relevant drug-drug interactions are caused mainly by an inhibition of P450-dependent reactions (19). In this respect, there is experimental evidence that cytochrome P450 (CYP) 1A1, CYP2C9, CYP2C19 and CYP3A4 are the main enzymes catalyzing the biotransformation of glibenclamide (20); while diclofenac is extensively metabolized by CYP2C9 and CYP3A4 enzymes $(7,21-23)$. In the present study, diclofenac concentrations were not affected significantly by the concomitant administration of $10 \mathrm{mg} / \mathrm{kg}$ of glibenclamide. The possible metabolic interaction was not sufficient to modify the diclofenac bioavailability. A partial explanation for this result is that both drugs are metabolized by several enzymes and the doses occupied in the present study (diclofenac $18 \mathrm{mg} / \mathrm{kg}$, p.o. plus glibenclamide $10 \mathrm{mg} / \mathrm{kg}$, p.o.) were not able to saturate the enzymes. This result indicates that glibenclamide does not interfere with pathways responsible for the metabolism of diclofenac.

The results showed a lack of pharmacokinetic drug interaction about diclofenac, but because the data were derived from single-dose administrations care should be followed in extrapolation to steadystate situations. Likewise, perhaps higher doses of glibenclamide could modify the diclofenac pharmacokinetic. Nevertheless, previous studies have demonstrated that systemic glibenclamide at the doses $\leq 10 \mathrm{mg} / \mathrm{kg}$ were sufficient to block the effects of analgesics $(15,17)$.

\section{Practical implications of these results}

The most important drugs in use for Type 2 Diabetes are the biguanide metformin and the sulfonylurea group. Glibenclamide, a potent second-generation sulfonylurea, which has been widely used in the management of non-insulin dependent diabetes mellitus in Europe since 1969 and in the United States since 1984, improves glucose tolerance mainly by augmenting insulin secretion (24). The action mechanism of glibenclamide consists in the inhibition of the ATPsensitive $\mathrm{K}^{+}$channels (12). In the present work, the sulfonylurea antidiabetic agent and ATP-sensitive $\mathrm{K}^{+}$channel blocker glibenclamide decreased the antinociceptive effect produced by diclofenac in the rat. According to our pharmacokinetic results, this effect was not due to an alteration in the diclofenac bioavailability. With this evidence, it is possible now to propose that after the systemic administration of diclofenac and glibenclamide, both drugs are absorbed and distributed to the action sites. When diclofenac is only administered, it produces an antinociceptive effect and when it is administered along with glibenclamide, the antinociceptive action is blockade. Up to now, there is not any clinical study about the pharmacokinetic interaction between diclofenac and glibenclamide. Likewise, it is necessary to realize a clinical study to evaluate the possible alteration of the analgesic effect when diclofenac is administered with glibenclamide.

A limitation of our study was that we did not use diabetic rats. In this respect, it has been demonstrated that chronic hyperglycemic states are able to alter the pain threshold and the renal function $(25,26)$. Nevertheless, the objective of the 
present study was not to evaluate the diclofenacglibenclamide interaction with these alterations. However, it would be of interest to examine that pharmacologic interaction in diabetic rat.

\section{CONCLUSION}

The results showed here displayed that systemic glibenclamide is able to block the diclofenacinduced antinociception in the rat formalin test. Besides, this antagonism was not produced by diminution in the bioavailability of diclofenac.

Finally, although in the present study we did not find alteration in the pharmacokinetics of diclofenac due to the glibenclamide treatment, this pharmacological agent should be further investigated to ensure its safe administration in diabetic patients with concurrent diclofenac administration.

\section{ACKNOWLEDGEMENTS}

Authors greatly appreciate the bibliographic assistance of Héctor Vázquez. Authors greatly appreciate the technical assistance of Martha Martínez-Corona, Marta Patricia González-García and Patricia González-Ramírez.

\section{REFERENCES}

[1] Todd PA, Sorkin EM. Diclofenac sodium. A reappraisal of its pharmacodynamic and pharmacokinetic properties, and therapeutic efficacy. Drugs, 1988; 35:244-285.

[2] Vane JR, Botting RM. Mechanism of action of anti-inflammatory drugs. Scand J Rheumatol, 1996; 102:9-21.

[3] Warner TD, Giuliano F, Vojnovic I, Bukasa A, Mitchell JA, Vane JR. Nonsteroid drug selectivities for cyclo-oxygenase-1 rather than cyclo-oxygenase- 2 are associated with human gastrointestinal toxicity: a full in vitro analysis. Proc Natl Acad Sci USA, 1999; 96:7563-7568.

[4] Ortiz MI, Torres-López JE, CastañedaHernández G, Rosas R, Vidal-Cantú GC, Granados-Soto V. Pharmacological evidence for the activation of $\mathrm{K}^{+}$channels by diclofenac. Eur J Pharmacol, 2002; 438:85-91.

[5] Ortiz MI, Granados-Soto V, CastañedaHernández G. The NOcGMP-K(+) channel pathway participates in the antinociceptive effect of diclofenac, but not of indomethacin. Pharmacol Biochem Behav, 2003; 76:187-195.
[6] Alves DP, Tatsuo MA, Leite R, Duarte ID. Diclofenac-induced peripheral antinociception is associated with ATP-sensitive $\mathrm{K}+$ channels activation. Life Sci, 2004; 74:2577-2591.

[7] Davies NM, Anderson KE. Clinical pharmacokinetics of diclofenac. Clin Pharmacokinet, 1997; 33:184-213.

[8] Fowler PD, Shadforth MF, Crook PR, John VA. Plasma and synovial fluid concentrations of diclofenac sodium and its major hydroxylated metabolites during long-term treatment of rheumatoid arthritis. Eur J Clin Pharmacol, 1983; 25:389-394.

[9] Zecca L, Ferrario P, Costi P. Determination of diclofenac and its metabolites in plasma and cerebrospinal fluid by high-performance liquid chromatography with electrochemical detection. J Chromatogr, 1991; 567:425-432.

[10] Torres-López JE, López-Muñoz FJ, CastañedaHernández G, Flores-Murrieta FJ, GranadosSoto V. Pharmacokinetic-pharmacodynamic modeling of the antinociceptive effect of diclofenac in the rat. J Pharmacol Exp Ther, 1997; 282:685-690.

[11] Al-Balla SR, El-Sayed YM, Al-Meshal MA, Gorda MW. The effects of cholestyramine and colestipol on the absorption of diclofenac in man. Int J Clin Pharmacol Ther, 1994; 32:441445.

[12] Edwards G, Weston AH. The pharmacology of ATP-sensitive $\mathrm{K}^{+}$channels. Annu Rev Pharmacol Toxicol, 1993; 33:597-637.

[13] Zimmermann M. Ethical guidelines for investigations of experimental pain in conscious animals. Pain, 1983; 16:109-110.

[14] Ortiz MI, Castañeda-Hernández G. Examination of the interaction between peripheral lumiracoxib and opioids on the $1 \%$ formalin test in rats. Eur J Pain, 2008; 12:233-241.

[15] Granados-Soto V, Terán-Rosales F, RochaGonzález HI, Reyes-García G, Medina-Santillán R, Rodríguez-Silverio J, Flores-Murrieta FJ. Riboflavin reduces hyperalgesia and inflammation but not tactile allodynia in the rat. Eur J Pharmacol, 2004; 92:35-40.

[16] Granados-Soto V, López-Muñoz FJ, Hong E, Flores-Murrieta FJ. Relationship between pharmacokinetics and the analgesic effect of ketorolac in the rat. J Pharmacol Exp Ther, $1995 ; 272: 352-356$

[17] Ortiz MI, Castañeda-Hernández G. Glibenclamide Reduces the Diclofenac-induced Anti-hyperalgesia in the Hargreaves Model of Thermal Hyperalgesia. Proc West Pharmacol Soc, 2006; 49:134-136. 
[18] Welch SP, Dunlow LD. Antinociceptive activity of intrathecally administered potassium channel openers and opioid agonists, a common mechanism of action?. J Pharmacol Exp Ther, 1993; 267: 390-399.

[19] Yuan R, Parmelee T, Balian JD, Uppoor RS, Ajayi F, Burnett A, Lesko LJ, Marroum P. In vitro metabolic interaction studies: experience of the Food and Drug Administration. Clin Pharmacol Ther, 1999; 66:9-15.

[20] Zharikova O, Fokina V, Nanovskaya $T$, Ravindran S, Hill R, Mattison D, Hankins GDV, Ahmed M. Identification of the major human hepatic and placental enzymes responsible for the metabolism of glyburide. Am J Obstet Gynecol, 2007; 197:S111.

[21] Leemann T, Transon C, Dayer P. Cytochrome P450TB (CYP2C): a major monooxygenase catalyzing diclofenac 4-hydroxylation in human liver. Life Sci, 1993; 52:29-34.

[22] Bort R, Mace K, Boobis A, Gomez-Lechon MJ, Pfeifer A, Castell J. Hepatic metabolism of diclofenac: role of human CYP in the minor oxidative pathways. Biochem Pharmacol, 1999; 58:787-796.

[23] Shen S, Marchick MR, Davis MR, Doss GA, Pohl LR. Metabolic activation of diclofenac by human cytochrome P450 3A4: role of 5hydroxydiclofenac. Chem Res Toxicol, 1999; 12:214-222.

[24] Luzi L, Pozza G. Glibenclamide: an old drug with a novel mechanism of action?. Acta Diabetol, 1997; 34:239-244.

[25] Arreola-Espino R, Urquiza-Marín H, AmbrizTututi M, Araiza-Saldaña CI, Caram-Salas NL, Rocha-González HI, Mixcoatl-Zecuatl T, Granados-Soto V. Melatonin reduces formalininduced nociception and tactile allodynia in diabetic rats. Eur J Pharmacol, 2007; 577:203210.

[26] Tesch GH, Allen TJ. Rodent models of streptozotocin-induced diabetic nephropathy. Nephrology (Carlton), 2007; 12:261-266. 